\title{
The Deep End: Pedagogy, Poetry and the Public Pool
}

\author{
Lucinda McKnight
}

Deakin University

\begin{abstract}
Diving in to new materialist theory, this paper explores what might be learnt at a public swimming pool, through poetry as arts-based research. Writing, sitting, thinking and swimming, the learner enters new spaces and atmospheres, where learning emerges as unpredictable and involving a whole range of human and non-human bodies. Public spaces, where we can think about causality and design without the strictures of school curriculum, may emerge as key sites for new understandings of learning where abiding humanist preoccupations can slip away. While this paper cannot offer the physical and material movement, touching, flesh, smelling, silicone, cotton and water of the poem as performed at the Public Pedagogies Institute conference in Melbourne in 2015, readers can still be prepared to get changed!
\end{abstract}

\section{Keywords}

public pedagogy, poetry, new materialist theory, public swimming pools 


\section{Pedagogy at the Pool}

The pedagogies of the public swimming pool may seem obvious: the strategies adopted by swimming teachers, with their stroke corrections and high fives, or the direct instruction employed by lifeguards and their whistles insisting on the correct use of lanes. There may be free seminars on nutrition and wall-mounted video broadcasts of correct lifting techniques for the gym, as at my local council-run sports complex in the eastern suburbs of Melbourne. These are the pedagogical regimes of public health in action, the kinds of common sense cultural constructs of teaching and learning in institutional settings that are the focus of much educational research (Sandlin et al 2010, p. 4).

Yet swimming, thinking and writing poetry with new materialist theory, different pedagogies come into play. This arts-based inquiry into pedagogy as a pool poem was performed in 2015, at the Public Pedagogy Institute's conference, Turning Learning Inside Out. This paper seeks to diffract (Barad 2007) this performance, channelling it through the narrows of writing a journal article, to create new patterns, ripple effects and movements in learning. This is a submission that eschews the idea that a paper might be 'delivered' at a conference and then published unchanged, and instead incorporates words, quotations, gestures and experiences of being at the conference, drawing these into a new assemblage, along with the artistry of poetic language. It forms a practical, tangible example of what new materialism might have to offer those who wish to expand perceptions of teaching and learning, through an introduction highlighting key concepts, a series of three extracts from the pool poem, and a conclusion suggesting directions for further study.

Taking this approach is an example of 'pedagogy in the interests of publicness' as Jennifer Sandlin (2015) described in her keynote opening the conference. This is pedagogy in which we engage relations of subjects, objects and embodied interactions which is both arts-based and critical. Conceptualising learning with new materialism in this public domain shifts sedimented ideas and frees us from school-dominated understandings of learning, or the model of the world as a 'giant school' (Sandlin 2015)- this is again the common sense model defining public pedagogy at the pool as being about the human-centred dictates of how to think and act ever more like an ideal human. Instead, and this is a 'tectonic' (Snaza \& Weaver 2015) change, we might move beyond the humanist project of education to recognise other, non-human bodies, and other, non-human publics in any pedagogical space.

New materialist theory, in particular that drawing on Karen Barad's concepts of intra-action and assemblage (2007) in which entangled agencies call each other into being, and Jane Bennett's tableaux of objects, for example, the 'glove-pollen-rat-cap-stick' (2010, p. 5) awaken us to the vibrant materiality of matter. Such theories encourage us to conceive of non-human agencies, to question human intentionality and to reject binaries such as that cleaving nature and culture. The notion of public versus private pedagogies is another troublesome split, complicated at the "public" pool where local schools hold their swimming lessons and sports carnivals. This paper suggests instead that learning in any assemblage, whether nominally public or private, might be realised differently though an alchemical forging of creative ways of knowing and emerging theory.

We might ask what curriculum at the pool would look like if we did not 'disavow the human's ecological entanglements' (Snaza \& Weaver 2015, p. 3), if we could set aside 'the desire to plan' and instead 'revel in potential drifts' (Snaza \& Weaver 2015, p. 3). What if we could relinquish the centrality of the human to curriculum (Gaztambide-Fernandes 2015)? A full genealogy of educational humanism is available elsewhere (Snaza 2015), but here we can turn instead to contemplating, if we can move beyond humanism, what is learnt at the pool, 
as a space more open to other bodies, to a more 'object-oriented ontology' (Snaza \& Weaver 2015 , p. 6) than that of the classroom. At the pool we can begin to become animal, become earth, and become machine, embracing the three challenges that face the post-human subject (Braidotti in de Freitas \& Curinga 2015, p. 261).

To achieve this aim, the paper performs the multidisciplinary incorporation of poetry, educational theory and philosophy, to think beyond curriculum as plan and pedagogy as choice in action. Instead of focusing only on human-driven strategy, we might look beyond the swimming teacher's modelling of correct freestyle and the life guard's whistle, to what else happens at the pool. This is not to present 'learning in the natural world' as opposed to 'learning in the cultural world' of the classroom, or to negate human agency, which is evident in institutional constraints that form part of any assemblage, even the most 'natural'. Instead these constraints become recognisable along with other forces at work.

This is not public pedagogy as an idealised space of freedom, a misapprehension to which Sandlin (2015) alerts us. We are not here to find out how we can be the best possible swimmers or the fittest possible rate-payers we can be, outside the constraints of school. We are here to countenance how we can think and be differently. So we do not assess squad training strategies, lap times, reward programs, outcomes, visitation figures, membership plans or income. Instead we challenge normative definitions of learning, whether in the classroom or in 'public' spaces; instead learning is always already active, decentred and beyond our illusions of control. We are aware of, and more than the 'control patterns' of local councils' public realms (Gray et al 2015).

Pedagogy is not a strategy (Dixon 2015), but instead a coalescence. Abstract instrumentalism dissolves in the pool, in water as transitional space and where, moving in a liquid medium, we become more aware of materiality. In water, our primordial home, we might see what has become invisible in the Anthropocene, notice animals, insects, ecologies. We enact Erin Manning's proposition for an entanglement, that we should 'believe not in thoughts that come from the desk, but thoughts that come from outside' (in Truman 2015), in this case outside of school learning. These ideas emerge with swimming, with the pool providing the pedagogical "pivot point" between movement or sensation and thought (Ellsworth 2005, p. 8).

I have expressed these thoughts through poetry, a disruptive medium contrasting with the familiar language of curriculum and pedagogy, of outline and lesson plan. In a more open, fragmented genre, with rules made to be broken, we might exist outside the distant intentionality of pedagogical plan-words, connect with what is more intense and urgent. Both Barad (2007) and Bennett (2010) conjure prose in their descriptions of the material world, but dense, evocative prose that, particularly in Bennett's case, leans towards poetry through the assemblage of disparate, juxtaposed elements. Inspired by these writers, I have used concrete imagery, sensory appeal and affect. As I performed the pool poem at the conference, I could see audience members grimace, shudder and smile, responding to language that is vibratory, sensitive to complexity and alive with metaphor. Personification, although a potentially humanising force bestowing human agency on animals or objects, also has the potential to bring matter to life (Bennett 2010, p. 120).

Poetry in/as research is said to be used to 'clarify and magnify our human existence' (Hirshfield cited in Faulkner 2009, p. 16). Poetry as new materialist or posthumanist artsbased research instead attempts to meet the universe halfway as Barad proposes in her title (2007), to flatten the figure of the human into the landscape of vital materiality, to challenge the emphasis on the humanist gaze in visuality ('clarify', 'magnify') and to explore other senses and capacities, including those that are not human. This poetry is open to what emerges, diffracting (Barad 2007) experience, rather than reflecting on what is seen, to enable alterna- 
tive understandings beyond binaries such as culture/nature. Academic discourse, water, skin, hydraulics, weariness all create each other, co-emerging as entangled phenomena, not merely as products of human labour or attention.

Swimming in a public space, moving, breathing, kicking, with theory swirling in my blood, I thought about learning, and scribbled notes on damp wads of paper in the changing room. I sought to diffract the experiences of the pool through the strictures of writing poetry, too, even free verse, not aiming for a poem as an aesthetic achievement, but put to work to materially constitute learning assemblages, and to respond to the call for us to reconsider our understanding of 'what counts as pedagogy' (Sandlin et al 2010, p. 4, emphasis in original). In the pool, I became immersed in the impossibility of thinking curriculum and pedagogy if we attempt to move beyond humanism, wrestled with this in every stroke carving the water's resistance and indulged this very endeavour as a masculinist, humanist trope of mastery.

I emerged changed, as in typical humanist narratives, alert to the White, human-centric, Anglo-centric nature of this public space in a world of increasing human diversity and rapidly decreasing ecological diversity. In the poem I play with this figure, the swimmer, poet, teacher, narrator, protagonist "I", and the grammatical imperative to be in charge and to order the world, along with the syntax and the lesson. I invoke paradoxes and ambiguities playfully and wonder how we can set the human aside, flatten people into the landscape. This is a creative space in which assumptions about pedagogy do not hold, where matter is active and alive, where water acts on multiple bodies, changing them, where there are synergies between species that learn from each other, between machinery, ducks, earth. What humans intend does not necessarily happen here. For readers to enter this space, I include here a series of three extracts from the longer poem, and invite all to go swimming with the following words.

\section{Extract One: Trip}

Why should this be a story then, with me driving to the pool and diving in.

For an answer. Climax. Resolution.

How do I get matter on here, on the page. I can't throw pool water at the glass.

Smear over sunscreen, fumes, mud and feathers.

I have to write this so the nature-culture assemblage springs

up from the page so you feel it in your body, so you think the world differently.

My pixel-minstrel words with computer, phone, train, study, spaghetti in your mouth, screaming kids, your memory of the lung-burn when you torpedoed a whole length the first time, with theory-little finger leaves the water first (backstroke)and all the pools

you've ever been in and will ever be in, sun, lane ropes, insects, chlorine, concrete. So it all

Rears back as new, not a reflection, a diffraction, through a poem.

(I keep coming together as new kinds of master- here I am, meet the poet).

What learning will happen at the pool.

Still the wrong question, still too pat, why do I even need a question, cue end of curriculum. 
I'm still asking it, the master interrogator, conquistador, inquisitor, find the pedagogy, deconstruct.

Oops, I'm not to deconstruct, naughty, so many ways to slip into those old grooves, those old lies:

$$
\begin{aligned}
& \text { anthropomorphise-lies } \\
& \text { narrativise-lies } \\
& \text { divinise-lies } \\
& \text { romanticise-lies } \\
& \text { essentialise-lies } \\
& \text { constructivise-lies }
\end{aligned}
$$

So many eyes on me to see if I trip up. So what if I do. As if I might not.

\section{Extract Two: Drift}

Pool lane etiquette for humans insists

we-they keep to the left.

Chinese-swimmer-pool-Is don't know this though. They stop and start, cross lanes, stand at ends. The word signs do not speak to them.

The rubber-capped lycra-men-Is swim at them and over them. At many pools in China there is only room for standing, not swimming. So there is bemusement at the pool, different paths, energies and purposes mapped over and over, forces and resistances that shift and change as they navigate each other.

Foam kickboards go fast lap years, then mould

and crumble, composing speed, decomposing matter.

Swimming is exercise for lap-Is and relaxation, recuperation for other, older Is.

Resistance teaches us to move, lubricates joints

increases range of motion, without purpose

but with profound effect. Moods change, endorphins are released, chemicals

react in our water-minds. Duck-human-swimmer-Is know never to go in the shaded lanes, water

is colder there, no waves of iridescent light shimmer over the tiles, wind ices the scalp, slides between feathers. The chi is different there.

When squad training starts, the energy ramps up. Young swimmer-Is cluster at the pool edge, muscle-hormone-mates, swing and stretch, dive in, chop, chop, water thrash and slosh, ten per lane. 
Duck-Is fly away honking, black flags against the sky, like those strung across the pool.

Beside the pool, a digger-I rests by scoured earth, strata exposed.

The digger's long arm has a shiny tendon, lax now with diesel exhaustion, but soon engine-adding to air soup, machine smoke inside and outside us.

Ducks walk here too and carry ancient clay

to the pool so the earth/water divide becomes pretence, and swimmer-Is swallow past-present-future molecule bodies of trees, and animals and people.

Boroondara Council owns our pool.

Boroondara is Wurundjeri ${ }^{1}$ for shady place. Not shady like it once was, though. Now there are White metal shade sail trees and thin, bare birch arms, white pocked,

Amidst the paperbarks.

A shade assemblage of absence, because everything was cleared and planted not long before after

Child-I was born.

The deciduous trees challenge the nature/cultured water

lie. Their leaves clog filters, disintegrate, penetrate nets, they make engines grind harder, roar louder, make the man-ager-I curse. They are nature/culture, seeds transported to mimic an alien landscape, to cultivate and colonise, to try to obliterate what went before, what goes on now when we say boroondara, when the dust blows, that is all of us, when Indigenous-swimmer-I dives in. Why would those tree-Is want to thwart the White-Anglo-Is that brought them, and yet they do. Unintended effect. Ripples of their leaf-drift spread, like those of the voyages of other migrants, through the pool and beyond. Invisible, indivisible. In the houses around the pool, newcomers hate the deciduous trees, cut those interlopers down

Meanwhile, man-ager-I focuses on water management, sanitation, adjusting acidity to that of human tears, tamping down the productive nature of elements driven to catalyse, calcify, metamorphise. Yet things move, change, reconfigure. Duck-Is mate, migrate, so do human-swimmer-Is. Human and non-human bodies transform the water body as it transforms them, making legs stronger, lungs fitter, parts weary,

1 The Wurundjeri are the traditional Indigenous owners of the land where the pool is located. 
muscles longer. We come together and apart,

all these Is, same-different, weather, people, animals, plants, machines, chemicals, elements, earth, in exchange-change. Human-swimmer-Is go home

with chlorine skin, scaly legs, an itch here and there, fungus in ears, warm, swim-tired, loose-limbed,

all those molecules ingested and adhered. Swimmer-I is still the pump-pool-Chinese-man-leaf-diesel-dirt-hair-wee-chlorine-bird assemblage that types these words.

\section{Extract 3: Curriculum}

I am made a different, diffracted, watery I, channelled through a narrow space, page-wide Through a lane, a pipe, a hole in the ground, spreading out now.

What does this breaking down

binaries, flattening agency achieve. Curriculum, imbued with intentionality, tells us man can

control water, that we swim in a pure, hygenic, neatly bounded pool, that changes us only in ways we intend,

that swimming is a masculinised mode of straight line

trajectories, guard-surveilled, athlete-inspired, inscribed and understood.

The official curriculum

is a sign on the wall that swimmers (ducks, new migrants, older people) cannot even read. Curriculum creates cause and anticipates effect, plans and instructs,

swim like this, dose like this, according to the rule book and all will continue in order and harmony, human supremacy confirmed.

Yet now we hear the tired pump valve that might close the pool, recognise the immigrant swimmers whose imported paths will multiply and change the way we swim.

What will the digger build next.

A fitness centre with a foyer reminding us that the Wurundjeri are custodians of the land. A pool with wide lanes for standing and walking and talking and swimming. A landscape friendly for duck nesting.

(Progress, and, alas, a hope-happy humanist ending. Hard to give up on better). 


\section{Conclusion}

This poem acknowledges an enduring humanist frame, yet demonstrably goes beyond common sense notions of learning how to swim at a pool, engaging at the deep end, with the nature of water, the politics of inclusion and the fictions to which we like to subscribe. Instead of finite human outcomes, we perceive fluid accommodation, exchange and intra-action. It is all too easy to forget that the pool pollutes, that pool water is the product of machinery and chemicals, and that the pool forms the habitat of myriad other creatures and the milieu of countless objects exerting their own agencies. We forget who and what might learn, who and what might teach.

Through poetry, we can complicate conceptions of what is learnt at the pool, in this notionally 'public' space. Art, theory and activity combine to transformative effect, creating new assemblages of pixels, computer hardware, ideas and movements, new formulations emerging now, as readers intra-act with these words, breathe and scroll down, becoming anew. Readers may take this experimental work further, critique it, notice my failures and limitations: the actions I describe at the end of the last extract above, for example, are only those that can be taken by humans, as proud custodians and explorers seeking an even better world. My attempts at multiple "I"s are inconsistent and inevitably human-informed. As the poem suggests, contradictions, binaries, reliance on pre-existing entities rather than emergent ones, human arrogance and assumption are all to be expected, as artists co-construct the meaning of a posthumanist, but not anti-humanist world, a distinction made in new materialist theory (Coole \& Frost, 2010, p.8). It is not possible to reject the human, but in working with creative strategies, it is possible to challenge human dominance.

What else might come, as we grasp, albeit with profoundly humanist language, at other possibilities? How might such entanglements be artistically felt and formed in relation to other public spaces, such as botanical gardens, football stadiums, foreshores, streets, playgrounds, city squares and nature reserves? How might we look back to the classroom, and bring new awareness to intra-action there, going beyond the bodily turn, which seemed to stall with humans? While curriculum theorists have identified concepts such as the hidden or implied curriculum which go beyond brute intentionality, these are still human-focused. What else is in play? What else is 'in the making' (James in Ellsworth 2005, p. 1)? These are questions to be asked of the Public Pedagogies Institute conference, too, where I scrawled wall flowers with viscous paint to make public art and shifted hips to the tango, in response to the call to let agentive music work on listeners.

So how could this poetic approach work to reconceptualise all these other spaces, to illuminate the assumptions we make in them, make us alert to and respectful of the agencies of matter, in a world in which ostensibly inert ocean-going plastics choke millions of birds and animals each year? How can we go further, using art to countenance the vitality of non-human bodies asserted by Bennett (2010)? How can we expand our notions of 'publics', too, and include human and non-human bodies, surpassing humanist preoccupations? This is a question that seems ever more pertinent as we approach the development of intelligent machines and the ethical dilemmas inherent with the increasing agencies of connected 'objects' forming the internet of things. The sphere of public pedagogy could be the space where such discussions can generatively and creatively take place. 


\section{References}

Barad, K 2007, Meeting the universe half-way: Quantum physics and the entanglement of matter and meaning, Duke University Press, London.

Bennett, J 2010. Vibrant matter: A political ecology of things, Duke University Press, London.

Coole, D \& Frost, S 2010, 'Introducing the new materialisms' In: Coole, D. \& Frost, S. (eds.) New materialisms: Ontology, agency and politics, Duke University Press, London.

De Freitas, E \& Curinga, M X 2015, 'New materialist approaches to the study of language and identity: Assembling the posthuman subject' Curriculum Inquiry, 45, 249-265.

Dixon, M 2015. 'Reading the pedagogical impact of space', Turning Learning Inside Out: Teaching and Learning Beyond the Classroom, Public Pedagogies Institute, Melbourne.

Ellsworth, E 2005. Places of learning: media, architecture, pedagogy, Routledge, New York

Faulkner, S. 2009. Poetry as method: Reporting research through verse, Left Coast Press, Walnut Creek, CA.

Gaztambide-Fernandez, R 2015, 'Thinking beyond the human'. Curriculum Inquiry, 45, 245-248.

Sandlin, J. 2015. 'Problematising public engagement within public pedagogy research and practice', Turning Learning Inside Out: Learning and Teaching Beyond the Classroom Conference, Public Pedagogies Institute, Melbourne.

Sandlin, J., Schultz, B. D. \& Burdick, J. 2010. 'Understanding, mapping and exploring the terrain of public pedagogy', in J Sandlin, BD Schultz, \& J Burdick (eds.) Handbook Of Public Pedagogy, Routledge, New York.

Snaza, N. 2015, 'Toward a geneaology of educational humanism' in N Snaza \& J Weaver (eds.) Posthumanism and educational research, Routledge, New York.

Snaza, N. \& Weaver, J. 2015, 'Education and the posthumanist turn' in N Snaza \& J Weaver (eds.), Posthumanism and educational research, Routledge, New York.

Truman, S E 2015, 'Emergent pedagogies: a new materialist consideration of group reading/writing practices', Turning Learning Inside Out: Teaching and Learning Beyond the Classroom Conference, Public Pedagogies Institute, Melbourne.

\section{About the Author}

Lucinda McKnight is a lecturer in pedagogy and curriculum, and a former secondary English/Humanities teacher and museum educator. She is also a published literary poet and fiction writer, and an award winning playwright. She has a keen interest in public pedagogy and learning beyond the classroom.

Lucinda McKnight

School of Education

Deakin University, Melbourne, Australia

1.mcknight@deakin.edu.au 